\title{
CEsifo WORKING

\section{Designing the Market for Job Vacancies: A Trust Experiment with Employment Centers Staff}

Guglielmo Briscese, Andreas Leibbrandt 


\section{Impressum:}

CESifo Working Papers

ISSN 2364-1428 (electronic version)

Publisher and distributor: Munich Society for the Promotion of Economic Research - CESifo

$\mathrm{GmbH}$

The international platform of Ludwigs-Maximilians University's Center for Economic Studies and the ifo Institute

Poschingerstr. 5, 81679 Munich, Germany

Telephone +49 (0)89 2180-2740, Telefax+49 (0)89 2180-17845, email office@cesifo.de

Editor: Clemens Fuest

https://www.cesifo.org/en/wp

An electronic version of the paper may be downloaded

- from the SSRN website: www.SSRN.com

- from the RePEc website: $\quad$ www.RePEc.org

- from the CESifo website: https://www.cesifo.org/en/wp 


\title{
Designing the Market for Job Vacancies: A Trust Experiment with Employment Centers Staff
}

\begin{abstract}
Trust is a key factor for the well-functioning of labor markets. We experimentally study the behavior of staff at competing employment agencies who serve as matchmakers between labor supply and demand. Employment agents can collaborate by sharing vacancies and job seekers at the risk of the other agent approaching the employer to place their own job seekers. In a framed field experiment with actual employment agents we test mechanisms to increase collaboration. We find that financial incentives to collaborate increase vacancy sharing but also increase the likelihood of the other provider approaching the employer to place their own job seekers. We also find that social incentives can backfire and decrease vacancy sharing unless employment agents have a perfect reputation. However, social incentives have a positive effect in increasing cooperative behavior. We discuss the implications for the design of incentives to increase trust in competitive markets like that of employment agencies.
\end{abstract}

JEL-Codes: D900, C920, J480.

Keywords: trust game, labor market, framed field experiment.

\author{
Guglielmo Briscese* \\ University of Chicago / IL / USA \\ gubri@uchicago.edu
}

\author{
Andreas Leibbrandt \\ Monash University / Clayton / Australia \\ andreas.leibbrandt@monash.edu
}

*corresponding author

December 17, 2020

We are grateful to the staff at the Applied and Behavioural Economics Section of the Australian Department of Employment, Skills, Small and Family Business for their support in designing and implementing the study, and to the staff at the job service providers who took part in the experiment. We thank Cameron Tan and Min-Taec Kim for excellent research assistance. This project is approved by Monash University Ethics Committee No. CF15/3056 - 2015001290. 
Trust lubricates labor markets and influences the decisions of all agents: employers, workers, and employment agencies that serve as matchmakers. Relationships between employers and employees are typically based on trust and not just on the clauses set in employment contracts (Charness, 2004; Kirchler et al., 1996; Fehr et al., 1993). Similarly, employers who outsource recruitment to employment agencies also need to trust they are recommending suitable job seekers. In turn, job seekers must trust the employment agency to place them into a suitable vacancy and trust the employer to deliver on promised benefits. A high level of trust among these actors, therefore, allows for an efficient exchange of resources in the presence of contracts that are incomplete by nature. Thus, it is beneficial for policy makers and managers to design mechanisms that foster trust.

In this paper, we experimentally study the competitive market of employment agencies where trust can increase collaboration. Specifically, we investigate employment agencies in Australia that compete with one another to match unemployed job seekers with vacancies and are remunerated by the government based on a performance framework that rewards sustainable job placements. In this setting, if an agency does not have a suitable job seeker for a vacancy they secured, they can potentially collaborate with a competing agency to seek a quality job match. However, this carries the risk that the competitor might 'poach' the employer to place job seekers from their own caseload in the future. Therefore, the incentives in the market for employment agencies may not foster trust among employment agencies, which in turn may lead to suboptimal job matches.

To help inform the design of policies that encourage trust among employment agencies, and thus collaboration and better job matches, we study the interaction of competing employment agents in framed trust games in which we vary incentives. Our framed field experiment renders it possible to measure trust and trustworthiness in the labor market in a controlled manner, using decision-making scenarios that resemble those faced by the agents on a regular basis ${ }^{1}$. We test two interventions to increase trust and collaboration that are budget

\footnotetext{
${ }^{1}$ We implemented as many feasible field variables as possible (actual employment agents as subjects, a social interaction that captures the key decisions of employment agents - see also Section II Experimental Design). A natural field experiment in this setting is unfeasible because it would introduce distortions to the market that are not allowed within the current contract framework between employment agencies and the government.
} 
neutral to the government. The first intervention involves changing financial incentives and distributing placement payments in a different manner. The second intervention involves social incentives and relies on a reputation mechanism. We study the effect of these incentives in increasing the sharing of job seekers and vacancies and reducing employer poaching.

The actual impact of these two types of interventions is, a priori, unclear. While the new financial incentives can make collaboration more attractive, they might also signal that collaboration is driven by self-interest and increase poaching, hence decreasing trust and collaboration. On the other hand, social incentives in the form of a reputation mechanism can signal trustworthiness and mitigate fear of becoming the victim of poaching (Luca, 2016; Grosskopf and Sarin, 2010; Bolton et al., 2005; Bohnet and Huck, 2004), but they might also harm collaborations if they create fear of retaliation or lead to strategic behavior if agents start caring more about their reputation than employment outcomes (Ely and Välimäki, 2003). Testing the effect of these mechanisms in a framed lab-in-the field study provides us with experimental evidence and a starting point for investigating other mechanisms.

Our experimental findings provide evidence on the scope of the tested interventions. We find that financial incentives to collaborate increase the sharing of vacancies but also increase poaching, potentially reducing the chances of repeated collaboration. Social incentives backfire and decrease vacancy sharing when agents do not have a perfect reputation. Even if agents have a perfect reputation, they do not increase vacancy sharing. However, social incentives have a positive effect on decreasing poaching. Further, we find that the effectiveness of these two types of incentives is conditional on the cooperative type of the agents: non-cooperative types, defined as those who always poach other agents' employers in the experiment, increase their levels of collaboration more than the other types in the presence of financial incentives, but are virtually indifferent to any type of reputation mechanisms. More cooperative agents significantly reduce their levels of collaboration in the presence of a bad reputation.

This paper has three main contributions. First, we study the role of trust in a previously untested but important context, that of employment agencies and their role in 
the functioning of labor markets. Whilst most labor market studies focus on the behavior of employers and job seekers, we zoom in on the behavior of employment agents who are responsible for a significant fraction of matches in the labor market. Second, we complement the literature on the scope of financial and social incentives to change behavior for better labor market outcomes. This is important as there is mixed experimental evidence on the suitability of social and financial incentives to foster trust (Parco et al., 2002; Fehr and List, 2004; Gneezy et al., 2011), and the existing evidence does not investigate their role in labor market matching. Third, we contribute to a growing literature that resorts to framed field experiments to inform policymaking when randomized control trials are unfeasible due to regulation constraints (Hannan et al., 2002; Haigh and List, 2005). We also offer new insights on how trust can be incentivized in a competitive market via low-cost or budget-neutral solutions. Where trust is lacking, government intervention may be beneficial to encourage market transactions. While individuals might have a stronger preference for government regulation when the level of trust towards others is low, government regulation can sometimes be costly and difficult to implement (Aghion et al., 2010). Instead, budget-neutral incentives might foster trust and collaboration in the market without the need for more complex contract reforms.

In the next section, we introduce the institutional context of our experiment, and how this framed field experiment can help inform policy changes. We then present the experimental design, showing how our decision-making scenarios resemble the tasks done by employment agents on a regular basis. We then present the experiment findings and discuss their implications.

\section{Institutional Background}

Our study takes place in the context of the Australian active labor policies in a regulated market for employment services - known as jobactive - which is composed of employment agencies (also referred to as job service providers) that are rewarded by the government 
based on a set of performance indicators. ${ }^{2}$. Job seekers who are claiming unemployment benefits and are deemed capable to work, are referred to employment agencies whose role is to find suitable employment opportunities. Employment agencies have an incentive to seek and secure vacancies from employers. Agencies work closely with employers to understand their recruitment needs and are responsible for referring suitable job seekers to an available vacancy.

Securing a vacancy might be more valuable to employment agencies as it can lead to repeat business with that employer. Job seekers deemed as 'work ready' are referred to a set of local providers by the governmental authorities and need to register with one provider to actively look for work in order to keep receiving income support. Agencies actively compete against each other and engage in business development activities with employers to secure vacancies. While agencies are tasked to assist both, job seekers and employers, by identifying suitable job matches, there are inherent frictions in making this match. For example, an agency may secure a vacancy but may not have a suitable job seeker, and vice versa. In these cases, vacancies may either remain unfilled or filled sub-optimally.

One solution to overcome these challenges is for employment agencies to collaborate with each other to improve the quality of job matches. Agencies can collaborate on a shared placement by sharing information on job seekers and vacancies that they are unable to fill internally, and such collaborations are encouraged by the government. However, trust issues may prevent agencies from collaborating. The agency that offers to share a vacancy needs to trust that the other agency will refrain from 'poaching' the employer to place job seekers from their own caseload in the future.

At the end of our experiment. we asked agents four consecutive questions on their average willingness to share vacancies and job seekers, and their perception of other agents' willingness to share vacancies and job seekers (the responses are summarized in Table 4). We

\footnotetext{
${ }^{2}$ The jobactive performance framework is based on principles of efficiency, effectiveness, quality and assurance. Job service providers are assessed by objective Key Performance Indicators (KPIs) that provide a rating of performance against which providers are remunerated by the Australian government agency. The KPIs are designed to incentivise long-term job placements, and providers can rely on a set of programmes and services partly fund by the government to achieve this goal. For more information: https://docs . employment.gov.au/documents/performance-framework-guideline
} 
observe that the average willingness to share and the perception of other agents' willingness to share, is low, both for vacancies and job seekers (never reaching an average of 2 , on a scale of 0-10). This suggests that vacancy and job seeker sharing is uncommon. Another noteworthy insight is the misperception of social norms: agents believe they share significantly more vacancies than others. This self-other discrepancy is in line with results from other studies on social norms (Bicchieri and Xiao, 2009; Schultz et al., 2007; Wenzel, 2005) and further reinforces the importance of testing the effectiveness of information treatments to reverse this misperception, as we do in the reputation mechanism in our experiment. ${ }^{3}$.

In sum, the market we are studying is affected by overall low levels of willingness to share and perceptions that others' willingness to share is even lower, proving its competitive nature. Studying the impact of financial and social incentives in a market where priors might be hard to shift makes our experiment interesting as a case study on how trust affects market outcomes. In sum, the competitive nature of the market we are studying is proved by the very low level of willingness to share overall and the perception that others' willingness to share is even lower. Studying the impact of financial and social incentives in a market where priors might be hard to shift makes our experiment interesting as a case study on how trust affects market outcomes.

\section{Experimental design}

To provide insight on how trust among employment agencies can be increased, we implement a novel version of the trust game in a framed field experiment with employment agents as participants. In the original version of the trust game by Berg et al. (1995), a player (sender) is endowed with an initial amount of capital that they can choose to share or not with another player (receiver). The portion of initial capital they choose to share is multiplied by the experimenters and offered to the receiver who can choose to keep everything for

\footnotetext{
${ }^{3}$ This discrepancy is not significant when it comes to sharing job seekers: agents report being more willing to share their vacancies than their job seekers but expect other agents to be more willing to share job seekers than vacancies. This supports the view that agents assign a higher value to vacancies than to job seekers, as we reflect in our experimental design.
} 
themselves or return a portion of the earned money to the sender. According to theoretical assumptions of full rationality, players are expected to keep the full amount (i.e., do not trust). However, experimental evidence shows that individuals consistently deviate from these theoretical predictions: senders split their initial amount of capital, and receivers reciprocate by returning significant shares. This leads to repeated successful exchanges that improve economic outcomes for everyone (Sapienza et al., 2013; Johnson and Mislin, 2011; Ashraf et al., 2006; Engle-Warnick and Slonim, 2004; Glaeser et al., 2000).

A total of 500 frontline staff across 35 employment agencies took part in the experiment, which was run on Qualtrics and took approximately 20 minutes to complete. Participants were recruited by an email sent by the Australian Department of Employment, Skills, Small and Family Business (herein 'the Department') in October 2017, which contained a link to the experiment, an explanatory statement, and a copy of the ethics study approval. The link took the participants to a landing page where the instructions and financial incentives of the experiment were explained. Once they read the instructions, participants could click on a button to begin the experiment with the first task. After they finished with the sixth task, there was a short survey. A copy of all study materials is available in the online Appendix. The financial incentives for the participants were as follows: in addition to a $\mathrm{A} \$ 3$ participation fee, in each of the six tasks, participants earned points depending on the choices they made, and the choices made by another matched anonymous participant. One of the six tasks was randomly chosen for payment to avoid income effects and hedging. In the task chosen for payment, we converted the points earned to real money using a conversion rate of 250 points $=\mathrm{A} \$ 1$. Participants received their compensation in the form of an electronic voucher to spend in any store of a common supermarket chain. In order to receive the voucher, participants had to provide their work email address at the end of the experiment. This also allowed us to control for multiple entries by the same subject ${ }^{4}$. Average earnings corresponded to A $\$ 16$ $($ minimum $=\mathrm{A} \$ 7$, maximum $=\mathrm{A} \$ 33)$.

\footnotetext{
${ }^{4}$ We detected only three attempts to participate twice in the experiment. For these three individuals we removed the data from their second time and only considered the choices they made the first time in both the analysis and the payment calculations. Participants could only use their institutional email address and not their personal email address to participate in the game.
} 


\section{$2.1 \quad$ Tasks}

Every subject played six tasks of a framed two-person sequential move trust game (Berg et al., 1995), in which we captured the key elements of collaboration. The first two tasks simulate the business-as-usual conditions, which provided us with a baseline. The remaining four tasks were used to determine the extent to which restructured financial (Tasks 3 and 4) and new social incentives (Tasks 5 and 6) influence the willingness of employment agents to trust and collaborate. To keep the instructions as self-explanatory as possible, the points for every possible outcome were displayed in each task, so participants knew their expected earnings depending on their choices and the potential decisions of a randomly paired agent. The matching of participants changed after each task and there was no feedback to avoid learning and reputation effects.

\subsubsection{Baseline (Tasks 1 and 2)}

Figure 1 shows the decision tree and possible outcomes in the first task. A copy of all tasks is provided in Appendix D. Player 1 refers to the first mover, or sender. In this example, Player 1 owns a vacancy but does not have a suitable job seeker to refer. They can earn money by sharing the vacancy with Player 2, who is also better off by collaborating, but can approach 5 the employer for future vacancies, leading to strong imbalances of payoffs. We choose the following parameters in the baseline:

- Job seeker $=1,000$ points, reflecting the value of a potential job placement

- Employer $=3,500$ points, representing the higher perceived value and the potential of repeat business

- Placement payment $=5,000$ points, in case of a successful job match

\footnotetext{
${ }^{5}$ In the paper we use the terms 'poach' and 'approach' interchangeably. Whilst the correct term to define the studied behaviour is 'poaching', we used 'approaching' in the experimental tasks to avoid a strongly negative framing from altering agents' preferences.
} 
- Collaboration bonus $=1,000$ points, to reflect a government policy to encourage collaboration

Figure 1: Task 1

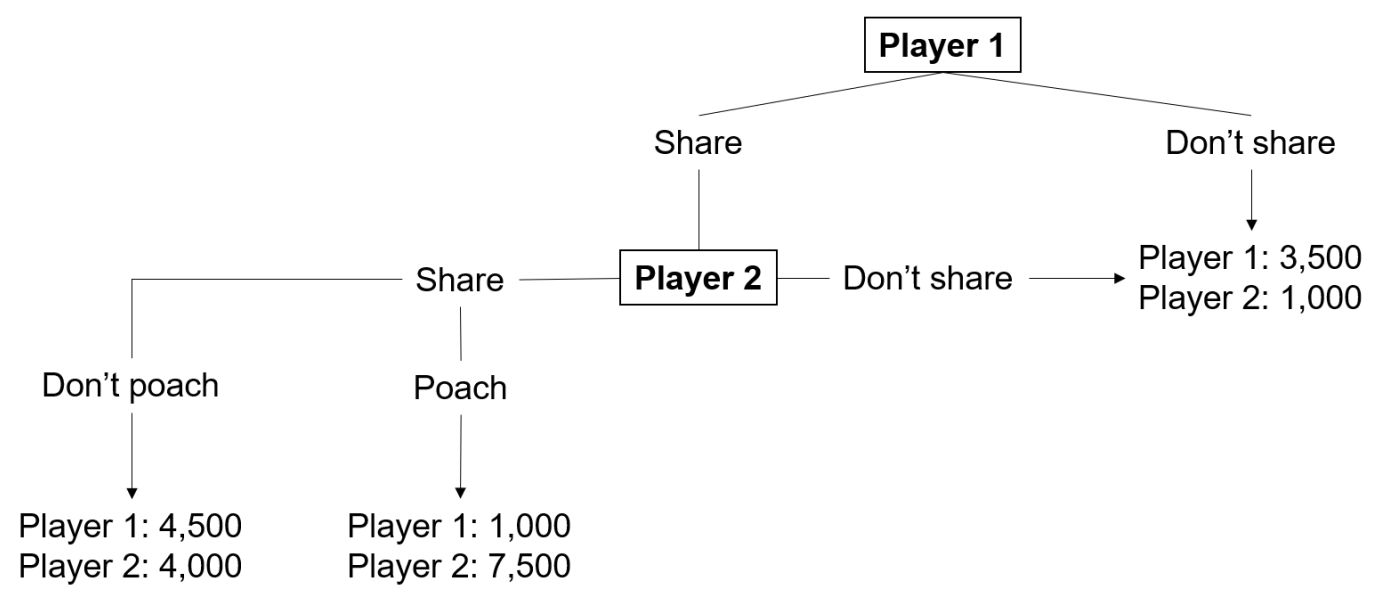

If Player 2 decides to collaborate and not approach, Player 1 keeps the employer for future placements (valued at 3,500) and receives a collaboration bonus $(1,000)$, while Player 2 receives the placement payment $(5,000)$ minus the value of the job seeker $(1,000)$ who has now exited their caseload. If Player 2 instead decides to approach, Player 1 only receives the collaboration bonus $(1,000)$, while Player 2 receives the placement payment $(5,000)$ and the employer value $(3,500)$ minus the value of the job seeker they placed $(1,000)$. In addition, Player 2 can also exit the trust game by not sharing their job seeker in which case they remain with 1,000 points and Player 1 with 3,500 points. ${ }^{6}$ Thus, capturing the elements in the field, trusting is quite risky for employment agents. Trust can only increase earnings by a maximum of 1,000 points but can decrease them by 2,500 points. Task 2 is identical to Task 1 but reverses the player types, i.e. all subjects play both roles: if a subject owned a vacancy in the first task (was Player 1), they would own a job seeker in task 2 (i.e., be Player 2).

\footnotetext{
${ }^{6}$ Note that this option is usually unavailable in the standard trust game. We decided to include it to mirror the naturally occurring environment.
} 


\subsubsection{Treatments}

In the subsequent four tasks, we test two incentive treatments: financial and social. Employment agents receive placement payments for placing job seekers, thus sharing vacancies is financially less attractive. To address this imbalance, the vacancy-sharing agency receives a collaboration bonus. ${ }^{7}$ We test whether redesigning financial incentives such that they may be perceived as more fair, can increase collaboration ${ }^{8}$. More precisely, in the financial treatment we implement an equal 50 percent split of placement payment between the two collaborating agencies. The changed incentives are summarized in Table 1. Similar to Task 1 and 2, Task 4 is identical to Task 3 but reverses the player types.

The social treatment consisted of a reputation mechanism. At the time of choosing whether they would share a vacancy or a job seeker, we showed participants information about the other agents' previous poaching behavior. Specifically, we showed them whether the other potential collaborator had: (i) always, (ii) once, or (iii) never approached other collaborators' employers in the past. Such a mechanism is attractive for various reasons. Firstly, it addresses the reputational issue where some agencies believe others are less likely to be collaborative by showing they have already collaborated in the past; secondly, it can influence cooperation via a signaling effect; and lastly, it is a relatively easy and low-cost intervention to implement in the field at a later stage. This means we considered treatments that could be scaled up nationally by the government at low cost. Task 6 is identical to Task 5 but reverses the player types.

\footnotetext{
${ }^{7}$ At the time of our study, the bonus applied to successful outcomes that led to job placements lasting at least 12 weeks.

${ }^{8}$ To check whether equal splits are indeed considered as fair we also ask participants in our end survey: "In this situation, where the other provider shares a vacancy and you transfer your job seeker, what percentage of the placement payment do you think it is fair for you to receive?". Participants answered this question by moving a slider, picking any integer value from 0 to 100. As conjectured, we observe that most respondents (70 percent) view the equal split as the fairest split.
} 
Table 1: Summary of payoffs across conditions

\begin{tabular}{|l|c|c|c|c|c|c|}
\hline \multicolumn{1}{|c|}{ Vacancy } & \multicolumn{2}{|c|}{ Baseline } & \multicolumn{2}{c|}{ Financial treatment } & \multicolumn{2}{c|}{ Social treatment } \\
\hline & $\begin{array}{c}\text { Do Not } \\
\text { Share }\end{array}$ & Share & $\begin{array}{c}\text { Do Not } \\
\text { Share }\end{array}$ & Share & $\begin{array}{c}\text { Do Not } \\
\text { Share }\end{array}$ & Share \\
\hline Do not place & {$[3500 ; 1000]$} & {$[3500 ; 1000]$} & {$[3500 ; 1000]$} & {$[3500 ; 1000]$} & {$[3500 ; 1000]$} & {$[3500 ; 1000]$} \\
\hline Place & - & {$[4500 ; 4000]$} & - & {$[7000 ; 1500]$} & - & {$[4500 ; 4000]$} \\
\hline $\begin{array}{l}\text { Place and } \\
\text { poach }\end{array}$ & - & {$[1000 ; 7500]$} & - & {$[3500 ; 5000]$} & - & {$[1000 ; 7500]$} \\
\hline
\end{tabular}

\begin{tabular}{|l|c|c|c|}
\hline \multicolumn{1}{|c|}{ Job seeker } & Baseline & Financial treatment & Social treatment \\
\hline Do not place & {$[1000 ; 3500]$} & {$[1000 ; 3500]$} & {$[1000 ; 3500]$} \\
\hline Place & {$[4000 ; 4500]$} & {$[1500 ; 7000]$} & {$[4000 ; 4500]$} \\
\hline $\begin{array}{l}\text { Place and } \\
\text { poach }\end{array}$ & {$[7500 ; 1000]$} & {$[5000 ; 3500]$} & {$[7500 ; 1000]$} \\
\hline
\end{tabular}

Table 1 summarizes the conditions and the potential payoffs in each task. Payoffs in the baseline conditions (tasks 1 and 2) are identical to each other but reversed (i.e. 3500;1000). These payoffs remain the same when participants decide not to collaborate in the subsequent treatment tasks - i.e. retaining the starting value of the job seeker and vacancy they owned. The financial treatment is designed to make collaboration more attractive, but also reflect the riskier nature of collaboration: where participants own a vacancy, they can double their baseline payoffs by collaborating, but the other agent can cancel that out by poaching the employer. Similarly, when participants own a job seeker, they are better off collaborating and poaching across all conditions, which would be the rational self-utility maximizing strategy. Indeed, the social treatment incentivizes collaboration, but in addition, it allows for more granular analysis to see whether participants are sensitive to the level of reputation of the other collaborator - that is, whether the other agent always, once, or never poached before.

Lastly, we control for possible ordering effects by randomly allocating half of the participants to the vacancy baseline first, and the other half to the job seeker baseline first. The order of the subsequent tasks is then inverted as a result (see instructions in the Appendix). We do this to understand the implications of trust and sharing by the first mover, depending on whether they own a vacancy or a job seeker, and whether this has repercussions in their subsequent decisions in the experiment. 


\subsubsection{Predictions}

The standard prediction in the trust game is that agents do not trust because they cannot enforce trustworthiness. In our context, this implies that agents never place their job seekers and always poach employers, regardless of the treatment. However, in trust games we typically observe considerable amounts of trust and trustworthiness (in the Berg et al. (1995) trust game, 24 out of 32 of respondents who received money returned some). Thus, we expect a significant level of job placements and some restraint from employer poaching in our experiment. The focus of this study is to investigate whether and how job placements and employer poaching are affected by standard financial and social incentives. The impact of these two types of interventions is, a priori, unclear. While the new financial incentives can make collaboration more attractive, they might also signal that collaboration is driven by self-interest and increase poaching, hence decreasing trust and collaboration. On the other hand, social incentives in the form of a reputation mechanism can signal trustworthiness and mitigate fear of becoming the victim of poaching (Luca, 2016; Grosskopf and Sarin, 2010; Bolton et al., 2005; Bohnet and Huck, 2004), but they might also harm collaborations if they create a fear of retaliation or lead to strategic behavior if agents start caring more about their reputation than employment outcomes (Ely and Välimäki, 2003). Testing the effect of these mechanisms in a lab-in-the field study provides us with experimental evidence on what works and for whom.

\section{$3 \quad$ Experimental Results}

We begin the analysis by looking at the behavior of employment agents when they own a vacancy and choose whether they want to share it with a competitor. We then look at the scenarios where the agents own a job seeker and choose to poach the employer from the other agency. Lastly, we look at the heterogenous effects of the treatments on the various cooperative types of the agents. 


\subsection{Treatment effects}

In general, we observe high rates of trust in our sample of employment agents, comparable to typical trust levels in games with a student subject pool (e.g. in Berg et al. (1995) and others). In the baseline task 1, 85 percent of participants trusted a competitor by sharing a vacancy. Figure 2 illustrates that there are also high likelihoods of sharing in the financial and social treatments but that there are significant differences across conditions. We can see that compared to about 85 percent of agents who share a vacancy in the baseline condition, a higher 92 percent share in the financial treatment condition $\left(\chi^{2}(1,500)=20.08, p<0.001\right)$. Social incentives are never quite as effective as financial incentives at increasing vacancy sharing. Instead, we find that a lower 78 percent of agents share when they know that the collaborator poached at least once $\left.\chi^{2}(1,500)=10.70, p<0.005\right)$, and this further decreases to about 63 percent when the other agent always poached in past collaborations $\left(\chi^{2}(1,500)=79.61, p<0.001\right) .{ }^{9}$ Only in the presence of perfect reputation - that is, when the agents know that the collaborator never poached before, does vacancy sharing stay at a level similar to that of the baseline scenario $\left(\chi^{2}(1,500)=0.11, p=0.745\right)$, but always remains lower than the financial incentives treatment.

\footnotetext{
${ }^{9}$ To compare binary outcomes throughout the paper we use the McNemar's test with ratio of paired proportions, which allows for analysis of differences within-sample before and after treatment.
} 
Figure 2: Vacancy sharing

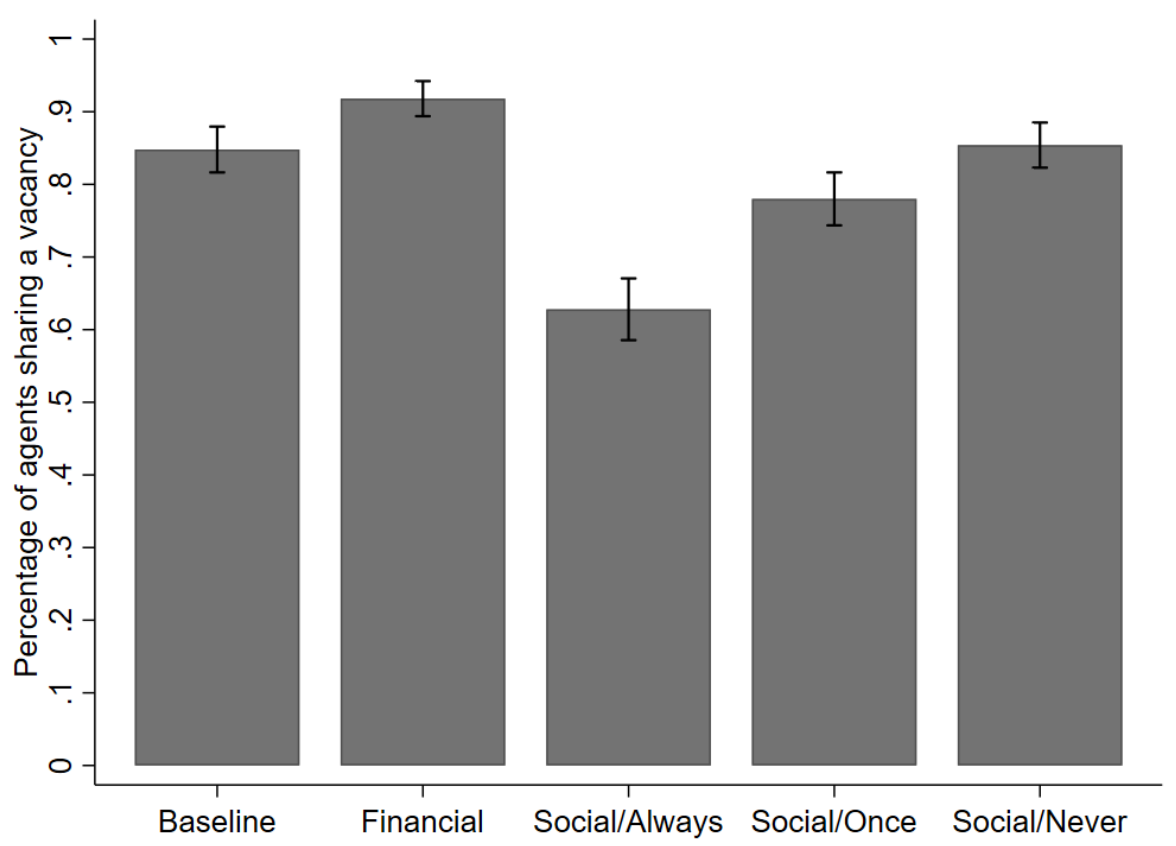

Notes. The figure plots the average vacancy sharing across conditions and relative standard error bars. Baseline refers to the control task without any type of incentive. Financial refers to the financial incentive treatment task. The three social treatments refer, respectively, to the treatment task where respondents knew whether the other agent poached "always", "once", or "never" before in previous collaborations.

It is important also that any treatment that is effective in increasing the sharing of vacancies among employment agents does not backfire. Thus, it is crucial to test the impact of the two types of incentives, financial and social, on the likelihood of employer poaching. In other words, we test whether financial or social incentives are effective in reducing poaching when the agent has the opportunity to do so every time they place a job seeker in a shared vacancy.

In the baseline condition (task 2), 97 percent of participants place their job seeker in a shared vacancy. This is higher than the baseline of vacancy sharing (85 percent), further confirming that employment agents value vacancies more than they value job seekers even in the absence of treatments. The rate of job seeker placement in a shared vacancy is constantly high and is not significantly different in the financial and perfect reputation treatments $\left(\chi^{2}(1,500)=0.89, p=0.3458\right.$, and $\left(\chi^{2}(1,500)=0.05, p=0.8185\right.$ respectively $)$ 
compared to the baseline. However, poaching behaviors do differ across treatments, as illustrated in Figure 3. We can see that in the baseline treatment, about 50 percent of employment agents place a job seeker and poach the other collaborator's employer, suggesting that non-cooperative behavior is common but not as much as it is perceived to be by the agents. Introducing financial incentives, however, increases poaching to more than 55 percent $\left(\chi^{2}(1,500)=3.80, p=0.051\right)$. In the case of negative reputation, agents do not increase poaching, but positive reputation is only effective when it's perfect, i.e., the agent sees that the collaborator never poached before $\left(\chi^{2}(1,500)=16.74, p<0.001\right)$.

Figure 3: Employer poaching

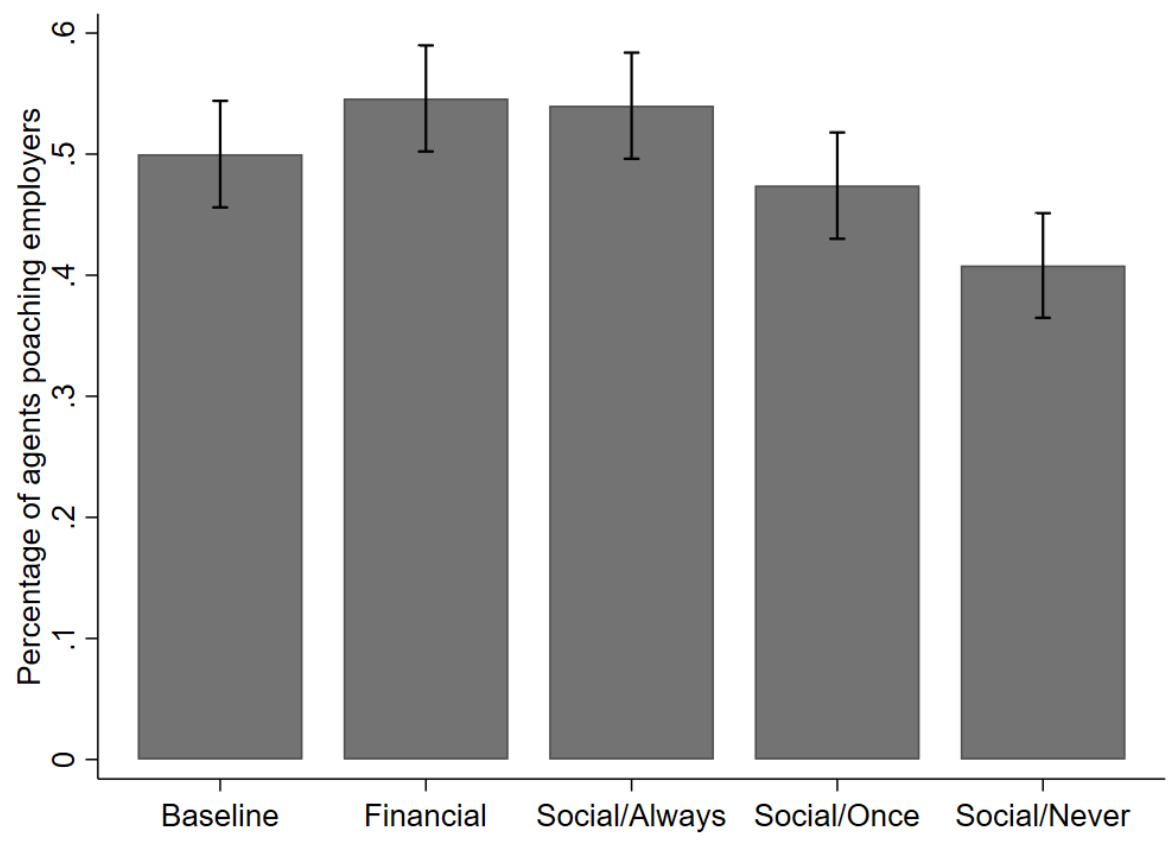

Notes. The figure plots the average likelihood of poaching the other agent's employer (conditional on placing a job seeker in a shared vacancy) across conditions, with standard error bars. Baseline refers to the control task without any type of incentive. Financial refers to the financial incentive treatment task. The three social treatments refer, respectively, to the treatment task where respondents knew whether the other agent poached "always", "once", or "never" before in previous collaborations.

To econometrically test for treatment effects on both vacancy sharing and employer poaching behaviors, we estimate the following model: 


$$
\text { Outcome }_{i t}=\alpha_{i}+\beta \text { Treatment }_{i t}+u_{i}+\epsilon_{i t}
$$

Model (1) estimates the likelihood of an individual $i$ to share a vacancy or to poach given individual-specific preferences for sharing and poaching, $\alpha_{i}$, where $i=1, \ldots \mathrm{n}$, and $\beta$ is the coefficient of the treatment effect on the likelihood of vacancy sharing or poaching for individual $i$. The two error terms refer to the between and within individual entity error terms. We estimate the model using a GLS random-effects model, accounting for individual preferences and characteristics, and for which group the agents belonged to (i.e. whether they played first the role of the vacancy or job seeker owner). The results are shown in Table 2 below. 
Table 2: Treatment effects on outcomes

\begin{tabular}{|c|c|c|c|c|c|c|}
\hline & & $\begin{array}{l}\text { Vacancy } \\
\text { sharing }\end{array}$ & & & $\begin{array}{l}\text { Employer } \\
\text { poaching }\end{array}$ & \\
\hline Constant & $\begin{array}{c}0.848^{* * *} \\
(0.016)\end{array}$ & $\begin{array}{c}0.667^{* * *} \\
(0.633)\end{array}$ & $\begin{array}{c}0.642^{* * *} \\
(0.647)\end{array}$ & $\begin{array}{c}0.500^{* * *} \\
(0.022)\end{array}$ & $\begin{array}{l}0.355^{* * *} \\
(0.0899)\end{array}$ & $\begin{array}{c}0.411^{* * *} \\
(0.091)\end{array}$ \\
\hline Financial incentive & $\begin{array}{c}0.070^{* * *} \\
(0.015)\end{array}$ & $\begin{array}{c}0.070^{* * *} \\
(0.015)\end{array}$ & $\begin{array}{c}0.070^{* * *} \\
(0.015)\end{array}$ & $\begin{array}{c}0.046^{* *} \\
0.020\end{array}$ & $\begin{array}{c}0.046^{* *} \\
0.020\end{array}$ & $\begin{array}{c}0.046^{* *} \\
0.020\end{array}$ \\
\hline $\begin{array}{l}\text { Social incentive/Always } \\
\text { (Negative reputation) }\end{array}$ & $\begin{array}{l}-0.220^{* * *} \\
(0.023)\end{array}$ & $\begin{array}{c}-0.220^{* * *} \\
(0.023)\end{array}$ & $\begin{array}{c}-0.220^{* * *} \\
(0.023)\end{array}$ & $\begin{array}{c}0.040^{*} \\
(0.0215)\end{array}$ & $\begin{array}{c}0.040^{*} \\
(0.0215)\end{array}$ & $\begin{array}{c}0.040^{*} \\
(0.0215)\end{array}$ \\
\hline $\begin{array}{l}\text { Social incentive/Once } \\
\text { (Imperfect reputation) }\end{array}$ & $\begin{aligned}- & 0.068^{* * *} \\
& (0.206)\end{aligned}$ & $\begin{array}{c}-0.068^{* * *} \\
(0.0206)\end{array}$ & $\begin{array}{c}-0.068^{* * *} \\
(0.0206)\end{array}$ & $\begin{array}{l}-0.026 \\
(0.021)\end{array}$ & $\begin{array}{l}-0.026 \\
(0.021)\end{array}$ & $\begin{array}{l}-0.026 \\
(0.021)\end{array}$ \\
\hline $\begin{array}{l}\text { Social incentive/Never } \\
\text { (Positive reputation) }\end{array}$ & $\begin{array}{c}0.006 \\
(0.018)\end{array}$ & $\begin{array}{c}0.006 \\
(0.018)\end{array}$ & $\begin{array}{c}0.006 \\
(0.018)\end{array}$ & $\begin{aligned}-0.092^{* * * *} \\
(0.022)\end{aligned}$ & $\begin{aligned}-0.092^{* * *} \\
(0.022)\end{aligned}$ & $\begin{aligned}- & 0.092^{* * * *} \\
& (0.022)\end{aligned}$ \\
\hline Risk & & $\begin{array}{c}0.005 \\
(0.006)\end{array}$ & $\begin{array}{c}0.006 \\
(0.006)\end{array}$ & & $\begin{array}{c}0.032^{* * * *} \\
(0.008)\end{array}$ & $\begin{array}{c}0.032^{* * *} \\
(0.008)\end{array}$ \\
\hline Patience & & $\begin{array}{c}-0.0009 \\
(0.005)\end{array}$ & $\begin{array}{r}-0.001 \\
(0.005)\end{array}$ & & $\begin{array}{r}-0.002 \\
(0.007)\end{array}$ & $\begin{array}{r}-0.002 \\
(0.007)\end{array}$ \\
\hline Altruism & & $\begin{array}{c}0.0213^{* * *} \\
(0.006)\end{array}$ & $\begin{array}{c}0.0206^{* * *} \\
(0.006)\end{array}$ & & $\begin{array}{r}-0.003 \\
(0.009)\end{array}$ & $\begin{array}{r}-0.004 \\
(0.009)\end{array}$ \\
\hline Ordering effects & & & $\begin{aligned}-0.0541^{* *} \\
(0.023)\end{aligned}$ & & & $\begin{aligned}- & 0.103^{* * *} \\
& (0.034)\end{aligned}$ \\
\hline No. of obs. $(\mathrm{N})$ & 2500 & 2500 & 2500 & 2500 & 2500 & 2500 \\
\hline No. of agents (id) & 500 & 500 & 500 & 500 & 500 & 500 \\
\hline
\end{tabular}

Notes. The models report the estimates of the effect of each treatment on the probability of sharing a vacancy (1) and poaching (2), measured by a binary variable on a panel dataset using GLS random-effects. Using a fixed-effects model yields almost identical results. Robust standard errors in parenthesis. ${ }^{* * *} p<0.01$; ${ }^{* *} p<0.05 ;{ }^{*} p<0.1$. Ordering effects is a dummy variable that refers to the order in which agents saw the group of tasks (either vacancy or job seeker tasks first).

Table 2 confirms the significant and positive effect of introducing financial incentives to increase vacancy sharing among agents. Similarly, any form of bad reputation - that is, when a person knows that the other agent poached every time they collaborated in the past or even just once before, has a significant effect on reducing vacancy sharing. Conversely, perfect reputation (i.e. knowing that the other agents never poached) has no significant effect. The significance and relative coefficients remain unchanged under different model specifications and after accounting for individual-specific characteristics, such as their preferences for risks, patience, and altruism as collected by the end-of-experiment questionnaire, or by accounting for the order in which agents played tasks in the experiment. 
RESULT 1: Financial incentives increase vacancy sharing. The implementation of a reputation mechanism leads to less vacancy sharing unless the employment agent has a perfect reputation, in which case the mechanism has no effect.

From Table 2 we can also see that the effect of the financial treatment is robust in increasing poaching, suggesting that while financial incentives might motivate more agents to share their vacancies, it will also lead to a higher likelihood of poaching. An effect of almost equal magnitude is observed when we introduce a reputation mechanism that notifies agents that the other collaborator always poached before. However, the opposite is true in the case of perfect reputation: when agents are told that the other collaborator never poached before, this significantly reduces the likelihood that the agent will poach, suggesting that a system of perfect reputation can induce agents to reciprocate examples of cooperative behavior, potentially leading to repeat collaboration.

RESULT 2: Financial incentives increase employer poaching. The implementation of a reputation mechanism decreases poaching if the employment agent has a perfect reputation but increases poaching if the employment agent has an imperfect reputation.

From the regression we can also see that ordering has a significant effect on decreasing both vacancy sharing and employer poaching. In our model, ordering effects is a dummy variable equal to 1 if the agent was randomly assigned to the group that saw the vacancy sharing tasks first. This seems to suggest a first-mover or learning effect: when agents are asked to share a vacancy before sharing a job seeker, they are less likely to share the vacancy. Similarly, this also reduces their likelihood of poaching employers.

Individual-specific social preferences are also worth noting. We see that a higher risk preference does not affect the likelihood of sharing vacancies, but does significantly increase the probability that an agent will poach others' employers. The opposite is true for a person's altruistic preferences: more altruistic agents are more likely to share vacancies but less likely (although not in a statistically significant way) to poach employers. This suggests that the 
employment agent type - i.e. whether they are more or less cooperative and altruistic - can influence the efficacy of the incentives. Motivated by this finding, in the next section we explore more closely these heterogeneous effects.

\subsection{Heterogeneous effects}

So far, we focused our analysis on the average treatment effects on all employment agents to estimate the overall effect of our interventions. While this is important, it is also crucial to make sure that these policies do not disadvantage the most cooperative employment agents and that their willingness to share vacancies is not crowded out. To estimate the effects of each incentive on the heterogenous types of agents, we distinguish in this section between three types of agents: (i) the most cooperative type, defined as those who never poach another agent's employer (24 percent of the sample); (ii) the non-cooperative type, defined as those who always poach (26 percent of the sample), and (iii) the semi-cooperative type, those who poached at least once but not every time (50 percent of the sample). We then look at whether

the financial and social incentives have any effect on the likelihood of the agent sharing a vacancy compared to the baseline task, accounting for individual-specific preferences. 
Table 3: Treatment effects on vacancy sharing, across agents' types

\begin{tabular}{lcccc}
\hline Vacancy sharing & All Sample & Cooperative & Semi-cooperative & Non-cooperative \\
\hline \multirow{2}{*}{ Financial Incentives } & $0.0700^{* * *}$ & $0.0738^{*}$ & $0.0726^{* *}$ & $0.0615^{* *}$ \\
& $(0.0198)$ & $(0.0382)$ & $(0.0309)$ & $(0.0298)$ \\
Social incentive/Always & $-0.220^{* * *}$ & $-0.238^{* * *}$ & $-0.302^{* * *}$ & -0.0462 \\
& $(0.0198)$ & $(0.0382)$ & $(0.0309)$ & $(0.0298)$ \\
Social incentive/Once & $-0.0680^{* * *}$ & $-0.0902^{* *}$ & $-0.0726^{* *}$ & -0.0385 \\
& $(0.0198)$ & $(0.0382)$ & $(0.0309)$ & $(0.0298)$ \\
Social incentive/Never & 0.00600 & 0.0574 & 0.00403 & -0.0385 \\
& $(0.0198)$ & $(0.0382)$ & $(0.0309)$ & $(0.0298)$ \\
Constant & $0.848^{* * *}$ & $0.828^{* * *}$ & $0.859^{* * *}$ & $0.846^{* * *}$ \\
$\mathrm{R}^{2}$ & $(0.0140)$ & $(0.0270)$ & $(0.0219)$ & $(0.0211)$ \\
$N$ & 0.111 & & & \\
No. of id & 2,500 & 610 & 1,240 & 650 \\
\hline
\end{tabular}

Notes. All models are fixed effects. Dropped observations are because either all positive or all negative outcomes ${ }^{* * *} p<0.01 ;{ }^{* *} p<0.05 ;{ }^{*} p<0.1$

From Table 3 we can see that financial incentives significantly increase vacancy sharing across all types of agents, but looking at the coefficients they seem to be most effective among the cooperative types, which is confirmed by a test on the equality of proportions comparing this type against the other types $(z=1.693, p<0.05)$. Non-cooperative agents appear to be indifferent to whether the other agent always poached before, not affecting their likelihood of sharing a vacancy. The opposite is true for the cooperative and semi-cooperative types, who significantly decrease their likelihood of sharing a vacancy if they know that the other agent always poached before. Knowing that the other agent poached once before is enough to significantly reduce the probability that cooperative and semi-cooperative agents will share a vacancy. In this case, the cooperative types are more sensitive to this effect, with a higher negative coefficient compared to the other types $(z=2.900, p<0.05)$. Lastly, social incentives in the form of perfect reputation - i.e. when the agent knows that the other agent never poached before - do not seem to have any effect regardless of the agent's cooperative type, confirming previous regressions from Table 2. 
RESULT 3: Financial incentives are effective at increasing vacancy sharing regardless of an agent's cooperative type. Social incentives in the form of perfect reputation do not have any effect regardless of the agent's cooperative type. Social incentives do not affect the vacancy sharing behavior of non-cooperative types, but significantly reduce that of more cooperative types in case of negative reputation.

\section{Conclusions}

Trust plays a key role in the efficient functioning of labor markets. Whilst there is some evidence on how trust shapes the relationship between employers and workers, there is a dearth of evidence on the role of trust played by staff at employment agencies who serve as matchmakers between the demand and supply of labor. We study the role of trust in a market where employment agencies compete to scout vacancies and place job seekers from their own caseload to receive compensation from the government. Where an agency does not have a suitable job seeker for an available vacancy, or vice versa, they could collaborate with a competing agency to achieve more stable job matches and improve labor market outcomes as a result. However, this risks other agencies poaching one's own employers to place their own job seekers in the future.

In a framed field experiment with 500 agents of competing employment agencies, we test the effectiveness of financial and social incentives in a trust game to increase collaboration. We find that financial incentives, in the form of an equal split of placement payments by the government, increases vacancy sharing across all types of agents, including the least cooperative ones, but reinforces competitive behavior by agents who tend to poach more. Social incentives in the form of a reputation mechanism, so that agents know the previous poaching behavior of each other, does not increase collaboration per se, but reduces the likelihood of poaching. We also find that the effectiveness of the incentives is sensitive to

the agent's cooperative type, with more cooperative agents being more responsive to bad reputation mechanisms. The two types of incentives we studied do not need to be mutually 
exclusive, and future research could investigate whether they complement each other. Lastly, our results also show that by leveraging on existing experimental methodologies, governments can introduce evidence-based and budget neutral incentives that may yield better societal outcomes. 


\section{Appendix}

Table 4: Perceived social norms

\begin{tabular}{|c|c|c|}
\hline No. & Questions & $\begin{array}{l}\text { Mean } \\
\text { (s.d.) }\end{array}$ \\
\hline 1) & $\begin{array}{l}\text { For every } 10 \text { vacancies you have available, how many do you think } \\
\text { you would normally share with another provider? }\end{array}$ & $\begin{array}{l}1.905 \\
(2.22)\end{array}$ \\
\hline 2) & $\begin{array}{l}\text { For every } 10 \text { vacancies other providers have available, how many do you think } \\
\text { they would normally share? }\end{array}$ & $\begin{array}{l}1.082 \\
(1.78)\end{array}$ \\
\hline 3) & $\begin{array}{l}\text { For every } 10 \text { job seekers you have available, how many do you think } \\
\text { you would normally place in another provider's vacancy? }\end{array}$ & $\begin{array}{l}1.68 \\
(2.36)\end{array}$ \\
\hline 4) & $\begin{array}{l}\text { For every } 10 \text { job seekers other providers have available, how many do you think } \\
\text { they would place in a shared vacancy? }\end{array}$ & $\begin{array}{l}1.596 \\
(2.31)\end{array}$ \\
\hline \multicolumn{3}{|c|}{$\begin{array}{l}\text { t-test }(1=2)=d f: 499 \mathrm{t}=11.75, \mathrm{p}<0.001 \\
\text { t-test }(3=4)=d f: 499 \mathrm{t}=0.40, \mathrm{p}=0.344 \\
\text { t-test }(1=3)=\text { df: } 499 \mathrm{t}=3.05, \mathrm{p}<0.01 \\
\text { t-test }(2=4)=\text { df: } 499 \mathrm{t}=-5.963, \mathrm{p}<0.001\end{array}$} \\
\hline
\end{tabular}

Notes. Table 4 reports the average values reported for each listed question by the 500 agents who took part in the experiment, with standard deviations in parenthesis. Answers were on a scale 0 to 10 , and all questions included at least one response with both extremes. 


\section{References}

Aghion, P., Y. Algan, P. Cahuc, and A. Shleifer (2010). Regulation and distrust. The Quarterly Journal of Economics 125(3), 1015-1049.

Ashraf, N., I. Bohnet, and N. Piankov (2006). Decomposing trust and trustworthiness. Experimental economics 9(3), 193-208.

Berg, J., J. Dickhaut, and K. McCabe (1995). Trust, reciprocity, and social history. Games and economic behavior 10(1), 122-142.

Bicchieri, C. and E. Xiao (2009). Do the right thing: but only if others do so. Journal of Behavioral Decision Making 22(2), 191-208.

Bohnet, I. and S. Huck (2004). Repetition and reputation: Implications for trust and trustworthiness when institutions change. American economic review 94(2), 362-366.

Bolton, P., M. Dewatripont, et al. (2005). Contract theory. MIT press.

Charness, G. (2004). Attribution and reciprocity in an experimental labor market. Journal of labor Economics 22(3), 665-688.

Ely, J. C. and J. Välimäki (2003). Bad reputation. The Quarterly Journal of Economics 118(3), $785-814$.

Engle-Warnick, J. and R. L. Slonim (2004). The evolution of strategies in a repeated trust game. Journal of Economic Behavior 65 Organization 55(4), 553-573.

Fehr, E., G. Kirchsteiger, and A. Riedl (1993). Does fairness prevent market clearing? an experimental investigation. The quarterly journal of economics 108(2), 437-459.

Fehr, E. and J. A. List (2004). The hidden costs and returns of incentives - trust and trustworthiness among ceos. Journal of the European Economic Association 2(5), 743-771.

Glaeser, E. L., D. I. Laibson, J. A. Scheinkman, and C. L. Soutter (2000). Measuring trust. The quarterly journal of economics 115(3), 811-846.

Gneezy, U., S. Meier, and P. Rey-Biel (2011). When and why incentives (don't) work to modify behavior. Journal of Economic Perspectives 25 (4), 191-210.

Grosskopf, B. and R. Sarin (2010). Is reputation good or bad? an experiment. American Economic Review 100(5), 2187-2204.

Haigh, M. S. and J. A. List (2005). Do professional traders exhibit myopic loss aversion? an experimental analysis. The Journal of Finance 60(1), 523-534.

Hannan, R. L., J. H. Kagel, and D. V. Moser (2002). Partial gift exchange in an experimental labor market: Impact of subject population differences, productivity differences, and effort requests on behavior. Journal of Labor Economics 20(4), 923-951. 
Johnson, N. D. and A. A. Mislin (2011). Trust games: A meta-analysis. Journal of Economic Psychology 32(5), 865-889.

Kirchler, E., E. Fehr, and R. Evans (1996). Social exchange in the labor market: Reciprocity and trust versus egoistic money maximization. Journal of Economic Psychology 17(3), $313-341$.

Luca, M. (2016). Reviews, reputation, and revenue: The case of yelp. com. Com (March 15, 2016). Harvard Business School NOM Unit Working Paper (12-016).

Parco, J. E., A. Rapoport, and W. E. Stein (2002). Effects of financial incentives on the breakdown of mutual trust. Psychological Science 13(3), 292-297.

Sapienza, P., A. Toldra-Simats, and L. Zingales (2013). Understanding trust. The Economic Journal 123(573), 1313-1332.

Schultz, P. W., J. M. Nolan, R. B. Cialdini, N. J. Goldstein, and V. Griskevicius (2007). The constructive, destructive, and reconstructive power of social norms. Psychological science 18(5), 429-434.

Wenzel, M. (2005). Misperceptions of social norms about tax compliance: From theory to intervention. Journal of Economic Psychology 26(6), 862-883. 